\title{
Gene Rearrangement: A Novel Mechanism for MDR-1 Gene Activation
}

Lyn A. Mickley, ${ }^{\star}$ Barbara A. Spengler, ${ }^{\ddagger}$ Turid A. Knutsen, ${ }^{\star}$ June L. Biedler, ${ }^{\ddagger}$ and Tito Fojo*

$*$ Medicine Branch, DCS, NCI, Bethesda, Maryland 20892; and ${ }^{\ddagger}$ Memorial Sloan Kettering Cancer Research Institute, New York 10021

\begin{abstract}
Drug resistance, a major obstacle to cancer chemotherapy, can be mediated by $M D R-1 /$ P-glycoprotein. Deletion of the first 68 residues of $M D R-1$ in an adriamycin-selected cell line after a 4;7 translocation, $t(4 q ; 7 q)$, resulted in a hybrid mRNA containing sequences from both $M D R-1$ and a novel chromosome 4 gene. Further selection resulted in amplification of a hybrid gene. Expression of the hybrid mRNA was controlled by the chromosome 4 gene, providing a model for overexpression of $M D R-1$. Additional hybrid mRNAs in other drug-selected cell lines and in patients with refractory leukemia, with $M D R-1$ juxtaposed $3^{\prime}$ to an active gene, establishes random chromosomal rearrangements with overexpression of hybrid MDR-1 mRNAs as a mechanism of acquired drug resistance. (J. Clin. Invest. 1997. 99:1947-1957.) Key words: drug resistance $•$ P-glycoprotein • MDR-1 • gene rearrangements
\end{abstract}

\section{Introduction}

With a decline in the number of new effective agents, resistance to chemotherapy has emerged as a major obstacle to further advances in the treatment of cancer. Multidrug resistance, a frequently encountered clinical problem, occurs when tolerance to one agent is accompanied by cross-resistance to unrelated compounds. There is a large body of evidence that acquired resistance to multiple natural products in vitro is mediated by P-glycoprotein, a cell surface glycoprotein originally described by Juliano and Ling that is encoded by the $M D R$-1 gene (1). P-glycoprotein functions as an energy-dependent drug efflux pump that results in decreased intracellular concentrations of drug $(2,3)$.

In the course of examining different P-glycoproteins for acquired mutations, a deletion in the $M D R-1$ gene of one cell line was identified as a novel mechanism for acquired resistance. The present study describes these results and the characterization of additional cell lines where random chromosomal rearrangements leading to hybrid $M D R-1$ mRNAs are identified as the mechanism of acquired resistance.

\section{Methods}

Tissue culture. The human colon adenocarcinoma cell line, S48-3s, and its selected sublines (Adr, ACT) were grown in a 1:1 mixture of

Address correspondence to Tito Fojo, Medicine Branch, DCS, NCI, Building 10, Room 12N226, 9000 Rockville Pike, Bethesda, MD 20892. Phone: 301-496-6313; FAX: 301-402-0172.

Received for publication 19 August 1996 and accepted in revised form 29 January 1997.

The Journal of Clinical Investigation

Volume 99, Number 8, April 1997, 1947-1957
IMEM + Ham's Nutrient Mixture F12 (Biofluids, Rockville, MD). The Adr 0.1, 1.0, and 10.0 sublines were maintained in $0.1,1.0$, and $10.0 \mu \mathrm{g} / \mathrm{ml}$ adriamycin, respectively. The subline, ACT 0.1 , was subcultured in $0.1 \mu \mathrm{g} / \mathrm{ml}$ actinomycin-D.

MCF-7 cells were grown in IMEM media. The resistant cell line, MCF TX400, was maintained in medium containing $400 \mu \mathrm{g} / \mathrm{ml}$ paclitaxel. Multidrug-resistant cell lines used as controls include: SW620 Vb300, DLD-1 Ad1000, KB C-1, and KB V-1 (4, 5).

$R$ Nase protection assay. A previously described genomic DNA fragment containing the native $M D R-1$ promoter was used as probe in the RNase protection assay (6). The hybrid chromosome 4/MDR-1 probe used in the RNase protection assay (see Fig. $5 E$ ) was made by cloning the hybrid chromosome 4/MDR-1 PCR product obtained by 5' RACE (GIBCO BRL, Gaithersburg, MD) into a pCR 2.1 vector obtained from Invitrogen Corp. (San Diego, CA). RNase protection analysis was performed by hybridizing total RNA with $2 \times 10^{5} \mathrm{cpm}$ of antisense RNA probes as described (7). The amount of RNA used in the hybridizations varied. $30-50 \mu \mathrm{g}$ of RNA were used for parental cells such as S48-3s, while 5-10 $\mu \mathrm{g}$ were used for the resistant cell lines with high levels of $M D R-1$.

Isolation and sequencing of novel hybrid messages by $5^{\prime} R A C E$. The $5^{\prime}$ RACE system (GIBCO BRL) was used to isolate the $5^{\prime}$ residues of the novel MDR-1 hybrid genes (S48-3s Adr 10.0, S48-3s ACT 0.1 , MCF TX400, and two acute leukemias). mRNA was reverse transcribed using a $3^{\prime} M D R-1$ gene-specific primer (GSP1 ${ }^{\mathrm{Adr}}$ : ${ }^{831} \mathrm{CAG}-$ ACAGCAGCTGACAGTCCAAGAACAGGACT ${ }^{799}$; GSP-1: ${ }^{-8}$ GGCTTCCTGTGGCAAAGAG ${ }^{-26}$ ). The dC-tailed cDNA was amplified by PCR using the $5^{\prime}$ anchor primer provided in the $5^{\prime}$ RACE kit and a second internal 3' $M D R-1$ gene-specific primer (GSP-2 ${ }^{\text {AdR: }}{ }^{299} \mathrm{TTC}-$ CCACCACCATATACAAC ${ }^{280}$; GSP-2: ${ }^{-81}$ AGCCTCACCACAGTG$\mathrm{ACT}^{-98}$ ) (8). Direct sequencing of the PCR product was performed using Sequenase (United States Biochemical Corp., Cleveland, $\mathrm{OH}$ ).

$P C R$. $1 \mu \mathrm{g}$ of RNA was reverse transcribed and amplified for the cycles described below in Figs. 2, 7, and 9. Primers are underlined in the figures. PCR of genomic DNA for quantitation of amplification was performed as described, omitting the reverse transcriptase step (9). The primers used are in Tables I and II.

Chromosomal mapping using somatic cell hybrids. Chromosomal assignment of the novel sequence isolated from S48-3s Adr 10.0 and the leukemia sample, ALL 2, were determined using the PCR and Poly A and D somatic cell hybrids (10). Primers used for somatic cell hybrid of S48-3s Adr 10 cells and ALL 2 are underlined in Figs. 2 and 9.

Fluorescent in situ hybridization. Chromosome preparations of the bromodeoxyuridine-synchronized cell lines (parental S48-3s cells and three adriamycin-resistant clones) were prepared according to previously described cytogenetic techniques (11). Fluorescent in situ hybridization $(\mathrm{FISH})^{1}$ was performed using whole chromosome painting kits for chromosomes 4 and 7 (Vysis, Inc., Downers Grove, IL and GIBCO BRL) (12). Each slide was hybridized with both probes and counterstained with 4,6 diamino-2-phenylindole.

Northern blot analysis. $10 \mu \mathrm{g}$ of total RNA from the S48-3s cell line and its three adriamycin-resistant sublines (Adr 0.1,1.0, and 10.0) were electrophoresed in a $1 \%$ agarose $/ 6 \%$ formamide gel. The gel

1. Abbreviations used in this paper: $C A S P, C D P$ alternately spliced product; $C D P$, CCAAT displacement protein; FISH, fluorescent in situ hybridization; HO-2, heme-oxygenase 2; NRF-1, nuclear respiratory factor-1. 
Table I. Relative Gene Amplification*

\begin{tabular}{lccccc}
\hline & $\begin{array}{c}M D R-1 \\
\text { (coding) }\end{array}$ & $\begin{array}{c}M D R-1 \\
\text { (promoter) }\end{array}$ & $\begin{array}{c}\text { Chr 4 } \\
\text { sequence }\end{array}$ & HO-2 & $C D P$ \\
\hline $\begin{array}{l}\text { S48-3sAdr 10.0 } \\
\text { S48-3s }\end{array}$ & 6.9 & 1.02 & 9.2 & 1 & - \\
$\begin{array}{l}\text { MCF-7 TX400 } \\
\text { MCF-7 }\end{array}$ & 23 & - & - & 1 & 42 \\
$\begin{array}{l}\text { S48-3s ACT 0.1 } \\
\text { S48-3s }\end{array}$ & 1.02 & - & - & 0.93 & 1 \\
\hline
\end{tabular}

Internal controls used for quantitation were chosen because there was no evidence of change in relative copy number in the pair of DNAs under study. The ratio is set at 1 . Internal controls used were as follows: for S48-3s Adr10.0/S48-3s and MCF-7 TX400/MCF-7, the HO-2 gene; for S48-3s ACT 0.1/S48-3s, the CDP gene. *Resistant cell line relative to parental.

was transferred onto nitrocellulose and hybridized with either the MDR-1 specific probe, 5A (residues 1306 to 2785), or a 248-bp chromosome 4 sequence probe (13).

Southern blot analysis. Genomic DNA isolated from S48-3s and adriamycin-selected sublines (Adr 0.1, 1.0, and 10.0) was digested with HindIII, and $10 \mu \mathrm{g}$ was run on a $1 \%$ agarose gel. The gel was transferred onto nitrocellulose and hybridized with the same probes as described in the Northern blot analysis (13).

FACS ${ }^{\circledR}$ analysis. Viable cell suspensions of S48-3s, S48-3s/Adr 10.0, S48-3s/ACT 0.1, MCF-7, and MCF-7 TX400 cells were incubated on ice with $50 \mu \mathrm{g} / \mathrm{ml}$ MRK16 mouse monoclonal antibody (Kamiya Biomedical Co., Thousand Oaks, CA), washed, and then incubated with $15 \mu \mathrm{g} / \mathrm{ml}$ FITC-labeled goat anti-mouse IgG (Vector Laboratories, Inc., Burlingame, CA). Cells were then washed and resuspended in PBS. A FACScan ${ }^{\circledR}$ flow cytometer (Becton Dickinson $\&$ Co., Mountain View, CA) was used to detect cell surface P-glycoprotein (14).

\section{Results}

Mutations in adriamycin-selected S48-3s cells. To screen for point mutations in $M D R-1$, we subcloned the $M D R-1$ cDNA from KB C-1 cells and used overlapping fragments in RNase protection assays. Fig. 1 shows the results using a 683-bp HaeIII probe (residues 110-792), with RNA from parental S48-3s cells, its adriamycin- and actinomycin-D-resistant sublines (Adr 0.1, Adr 1.0, Adr 10, ACT 0.1), KB C-1 and KB V-1. The source of the cDNA (KB C-1 cell line) has unique point mutations at 676, 690, and 691 (coding sequence 540, 554, 555); consequently, full protection of the 683-bp HaeIII probe was seen only with RNA from KB C-1 cells. This fragment with unique point mutations was used as a probe because it pro- vides an "internal control" for RNase digestion, since all RNAs differ from it and will be cleaved at the sites of these mismatches. RNA from the majority of cell lines demonstrate a pattern similar to that seen with S48-3s Act 0.1 and KB V-1 RNAs: fragments of $567,116,102$, and $101 \mathrm{bp}$ as a result of mismatches at 676, 690, and 691. (The 116-bp fragment is poorly visualized because mismatches at 690 and 691 result in cleavage to 102 and 101 bp.) In contrast, RNA from the S48$3 \mathrm{~s} /$ Adr sublines protects fragments of 116,102 , and $101 \mathrm{bp}$, but not 567. These samples exhibit two different patterns, acquired at successive steps. In S48-3s/Adr 0.1, a 474-bp fragment is observed (a result of a 91-bp deletion as shown below). In the next step (S48-3s/Adr 1.0), two additional fragments appear ( 255 and $219 \mathrm{bp}$ ) as a result of an acquired conserved mutation $(\mathrm{G} \rightarrow \mathrm{A})$ at residue 457 (data not shown). Further analysis using a fragment containing residues 393-792 resulted in complete protection of this probe by all RNAs, excluding the possibility that any residues contained within this fragment were missing. Instead, this observation suggested that the 474-bp fragment resulted from a deletion in the $5^{\prime}$ end of the region encompassed by the 683-bp HaeIII probe, a prediction that was subsequently confirmed as consisting of the first 68 residues of the coding sequence and 23 residues from the $5^{\prime}$ UTR (sequence analysis and corroborating evidence described below). Finally, it is apparent from examination of the RNase protection that the S48-3s/Adr cell lines do not express significant levels of "wild-type" transcript, since protection of the 567-bp fragment is not seen, nor was it observed in longer exposures.

The predicted deletion in the $5^{\prime}$ end of the 683-bp HaeIII fragment was further investigated by $5^{\prime}$ extension analysis of RNA from the S48-3s/Adr 10.0 subline and two multidrug resistant $\mathrm{KB}$ sublines using a $3^{\prime}$ primer complimentary to residues 280-299 of MDR-1 (not shown). With KB V-1 and KB C-1 RNA, extension products of 299 and 303 bp were obtained, (transcription starts at residues +1 and -4 ) (6). With RNA from S48-3s/Adr 10.0, a 345-bp product was obtained.

To determine the sequence of the 345 -bp product, the $5^{\prime}$ RACE system and primers GSP1 ${ }^{\mathrm{Adr}}$ and GSP2 ${ }^{\mathrm{Adr}}$ were used to clone the $5^{\prime}$ region of the $\mathrm{S} 48-3 \mathrm{~s} / \mathrm{Adr} 10 \mathrm{MDR}-1$ transcript. Fig. $2 A$ presents the sequence of the $5^{\prime}$ region of the $M D R-1$ mRNA from S48-3s Adr 10 cells. This sequence includes 250 bp of non-MDR-1 residues (capital letters), not found in the Genbank/EMBL/DDBJ database (but localized to chromosome 4 as detailed below). Thus, the $M D R-1$ mRNA in these cells is a hybrid message of non-MDR-1 and $M D R-1$ sequences. Examination of the sequence suggested the first 68 residues (137-204) of the $M D R-1$ coding sequence were missing and residues $\mathrm{A}$ and $\mathrm{G}$ (double underline) were part of the non-MDR-1 sequence. This appeared likely because intron 2

Table II. Primer Sequences of Genes in Table I

\begin{tabular}{|c|c|c|}
\hline Gene & 5' Primer & 3' Primer \\
\hline$M D R-1$ (coding) & $\begin{array}{l}{ }^{+546} \text { GCCTGGCAGCTGGAAGACAAA } \\
\text { TACACAAAATT }^{+577}\end{array}$ & $\begin{array}{l}{ }^{+831} \text { CAGACAGCAGCTGACAGTCCA } \\
\text { AGACAGACT }^{+799}\end{array}$ \\
\hline$M D R-1$ (promoter) & ${ }^{-194}$ AGAGGTGCAACGGAAGCC ${ }^{-177}$ & ${ }^{-8}$ GGCTTCCTGTGGCAAAGAG $^{-26}$ \\
\hline Chr 4 & ${ }^{+1} \mathrm{AGCTCGCTCAGCCGCCGGGA}^{+17}$ & ${ }^{+119}$ TTCCACCGCCTCCTCCAA $^{+103}$ \\
\hline$C A S P$ & ${ }^{-15} \mathrm{ATCAGCCGCTCACTCCGT}^{+3}$ & ${ }^{+82}$ CTGCAGCTGCTGTAAATCAA $^{+63}$ \\
\hline$H O-2$ & ${ }^{-22}$ CCTGAGGGAGTCGCTGAC ${ }^{-5}$ & ${ }^{+45}$ CTGCCGCAGGTCGCTGT $^{+29}$ \\
\hline
\end{tabular}



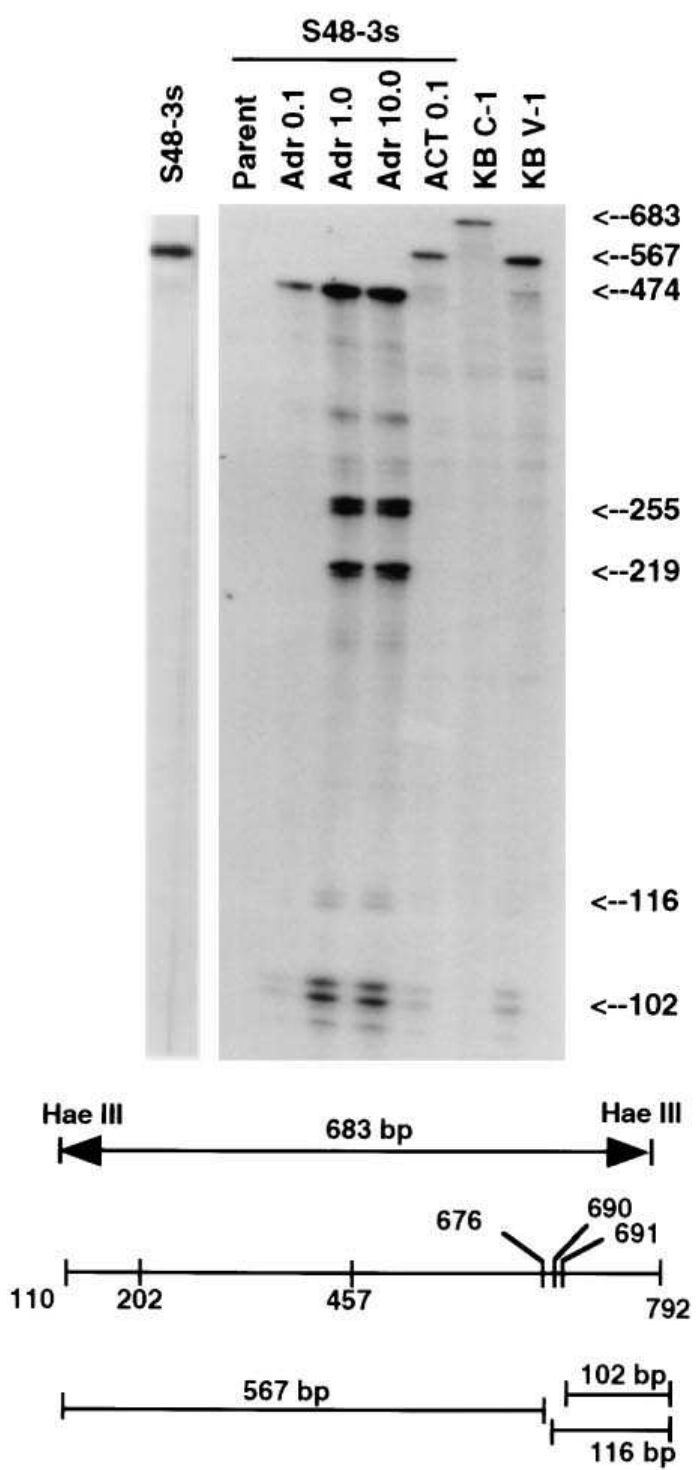

Probe (Source: KB C-1)

$676,690,691$ : Mutations unique to KB C-1

WT: ACT $0.1, \mathrm{~KB} \mathrm{V-1}$ and S48-3s

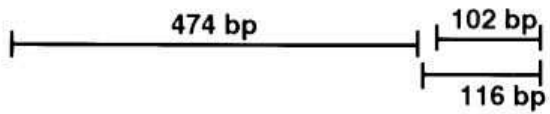

Fragments protected by S48-3s/Adr 0.1: acquired deletion of residues 5' to 202

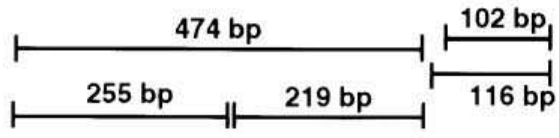

Fragments protected in S48-3s/Adr 1.0 and S48-3s/Adr 10: acquired deletion of residues 5' to 202 and an acquired mutation at 457

Figure 1. RNase protection analysis with the 683-bp HaeIII probe (residues 110-792). The fragments obtained and their origins are described in the lower half of the figure. WT, wild type.

(estimated at $4.3 \mathrm{~kb}$ ) is present between residues 204 and 205 (located in exons 2 and 3, respectively) and could have been the site of a rearrangement (15) (see Fig. 3, below). Additional studies were performed using $M D R-1$-specific primers, and primers corresponding to the non- $M D R-1$ sequence. Fig. $2 B$ shows the expression of the novel non- $M D R-1$ sequences using primers corresponding to residues +1 to +17 and +248 to +231 . Expression in parental S48-3s cells could be demon- strated after amplification of cDNA from $1 \mu \mathrm{g}$ RNA for only 22 cycles $(M D R-1$ must be amplified six to eight additional cycles to obtain a comparable signal in parental cells). Expression increased with drug selection as this non-MDR-1 sequence was amplified (see below) and expressed as a hybrid message with the $M D R-1$ sequences (overexpression of these sequences is also shown below in Fig. $5 C$ ). Fig. $2 C$ depicts expression of the hybrid 345-bp fragment. For this analysis, primers 
A.

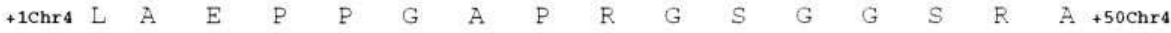
AG CTC GCT CAG CCG CCG GGA GCA CCC AGA GGG ACG GGA GGC AGC CGC GCA

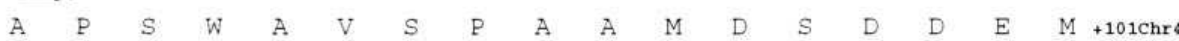

GCC CCG AGC TGG GCA GTG TCC CCA GCC GCC ATG GAT AGC GAC GAC GAG ATG

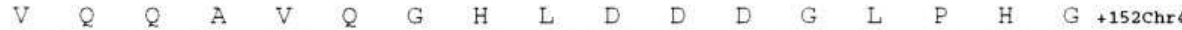
GTG GAG GAG GCG GTG GAA GGG CAC CTG GAC GAT GAC GGA TTA CCG CAC GGG $F \quad C \quad T \quad V \quad T \quad T \quad S \quad S \quad T \quad D \quad R \quad F \quad E \quad G \quad N \quad F \quad V+203 c h r 4$ TTC TGC ACA GTC ACC TAC TCC TCC ACA GAC AGA TTT GAG GGG AAC TTT GTT $\begin{array}{lllllllllllllllllll}H & G & E & K & N & G & R & G & K & F & F & F & F & D & G & S & +208 M D R\end{array}$ CAC GGA GAA AAG AAC GGA CGG GGG AAG TTC TTC TTC TTT GAT GGC AGt gaa aaa gat aag aag gaa agg aaa cca act gtc agt gta ttt tca atg ttt cgc $+259 M D R$

tat tca aat tgg ctt gac aag ttg tat atg gtg gtg gga a

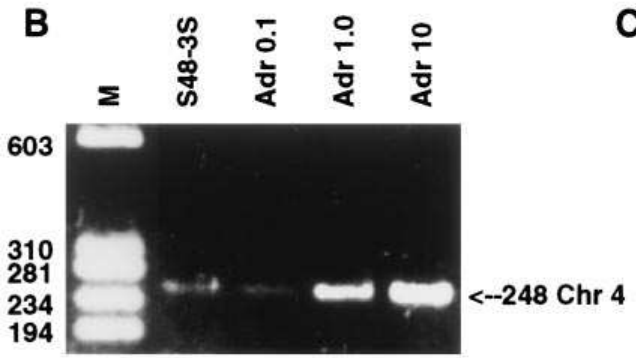

c

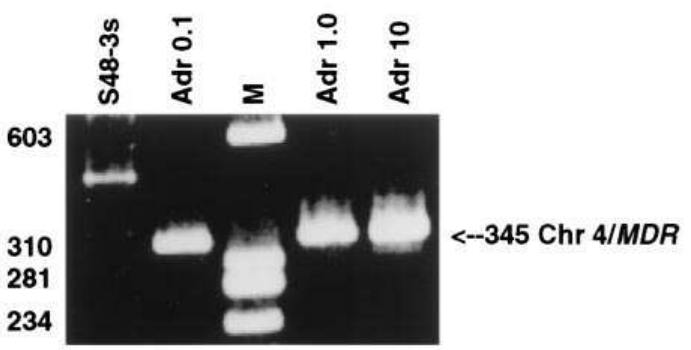

D

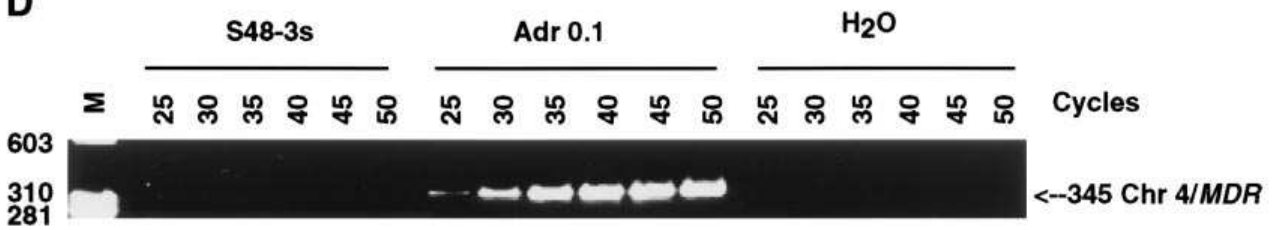

Figure 2. (A) Nucleotide and amino acid sequence of novel residues (upper case) $5^{\prime}$ to $M D R-1$ (lower case) in S48-3s Adr cells. 250 residues (localized to chromosome 4, see Fig. 3) are present $5^{\prime}$ of nucleotide +205 of $M D R-1$. Underlined sequences are primers for the PCR studies in $B-D$. Bold underline identifies potential start sites of translation of hybrid protein; potential amino acid sequence is shown. (B) Expression of 248-bp chromosome 4 fragment in parental and drugresistant sublines. Primers used were $5^{\prime}:+1 \mathrm{Chr} 4$ to +17Chr4; 3': +248Chr4 to +231Chr4 (1 $\mu \mathrm{g}, 25$ cycles). (C) Expression of hybrid 345-bp Chr4/MDR fragment in parental (none detected) and adriamycin-resistant cells. Primers used were $5^{\prime}:+1 \mathrm{Chr} 4$ to $+17 \mathrm{Chr} 4$; $3^{\prime}:+299 M D R$ to $+280 M D R$ (1 $\mu \mathrm{g}, 25$ cycles). (D) Expression of hybrid transcript in parental (none detected) and S48-3s Adr 0.1 cells. Primers used are described in $C$. corresponding to residues +1 to +17 of the non-MDR -1 (Chr 4$)$ sequence and 299 to 280 of $M D R-1$ were used. A signal could not be discerned in parental cells, but was present in the three adriamycin-selected sublines at readily detectable levels. Support that expression of this hybrid mRNA is an acquired phenotype is shown by the PCR results in Fig. $2 D$. The studies in Fig. $2 D$ were performed after preliminary experiments demonstrated that the primers and conditions used could sustain exponential amplification over a broad concentration range and over a range of amplification cycles. As shown, even after amplification of cDNA derived from $1 \mu \mathrm{g}$ of RNA for $50 \mathrm{cy}-$ cles, a product could not be detected in parental S48-3s cells. In contrast, a clear signal could be seen after 25 (and even 22) cycles in RNA from S48-3s Adr 0.1 cells. Thus, expression is significantly greater in resistant cells.

That intron 2 was the site of a rearrangement was confirmed by the PCR analysis shown in Fig. 3 using genomic DNA from parental and S48-3s Adr 10 cells. The same $3^{\prime}$ primer (253-228, located in exon 3) was used in these PCR reactions. For parental S48-3s cells, a $5^{\prime}$ primer corresponding to residues 149-169 of $M D R-1$ gave a 4.3-kb product corresponding to intron 2. A similar product was obtained with DNA from Adr 10.0 cells, indicating the existence of at least one normal $M D R-1$ allele in this subline. Sequence analysis of this product demonstrated the expected $M D R-1$ sequences at both ends ( $M D R-1$ exon 2 residues 149-204 at the $5^{\prime}$ end and $M D R-1$ exon 3 residues $205-253$ at the $3^{\prime}$ end). In addition, with DNA from Adr 10.0, a second product of $\sim 5.5 \mathrm{~kb}$ was obtained when a $5^{\prime}$ primer corresponding to the non-MDR-1 sequence (residues $+202-+224$ of Fig. 2) was used. Sequence analysis of this $5.5-\mathrm{kb}$ product revealed non-MDR-1 residues $+202-+250$ (Fig. 2) at the 5' end and $M D R-1$ exon 3 sequences (205-253) at the $3^{\prime}$ end. This confirmed a rearrangement in intron 2. Parenthetically, it should be stated that although the resistant cells contain at least one normal MDR-1 allele (actually most likely two as shown in Fig. 4), expression from this (these) allele(s) is not detected in Fig. 1 because, compared with parental cells, only $1 / 10$ as much RNA was analyzed for the resistant cell lines and, in the exposure shown, expression in parental cells of the wild-type alleles is poorly detected.

Cytogenetic evidence establishing a chromosomal rearrangement as the event responsible for the hybrid mRNA in the adriamycin-selected S48-3s cell lines, and the increase in $M D R-1$ expression is shown in Fig. 4. Initially, analysis of G-banded metaphase chromosomes was carried out; but although these results were consistent with a rearrangement, they were not confirmatory (not shown). Further studies using FISH analysis, however, demonstrated conclusively that a translocation had occurred (Fig. 4). Initially, we used primers corresponding to the non-MDR-1 sequence and somatic cell 


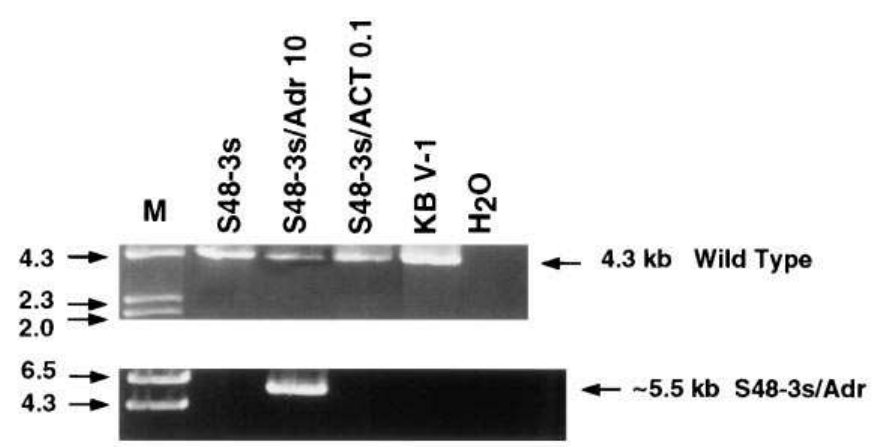

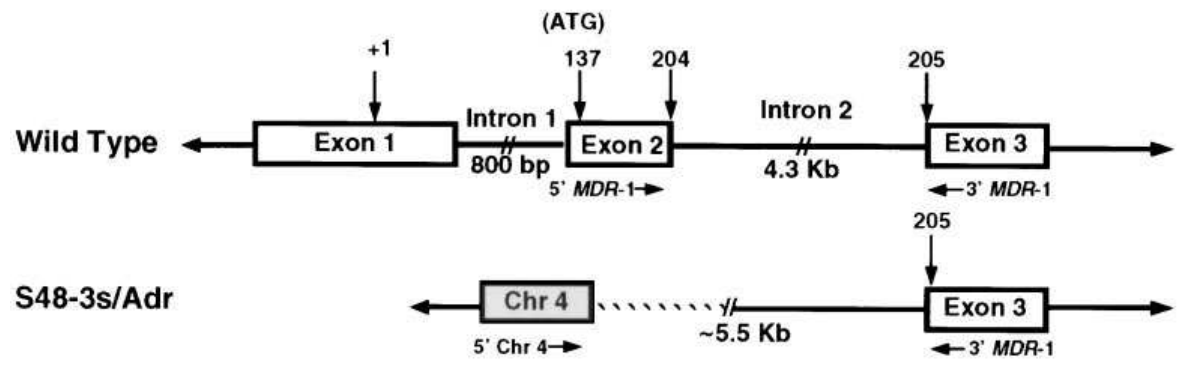

Figure 3. PCR amplification demonstrating the appearance of a new intron fragment in adriamycin-selected S48-3s cells. Primers for the upper PCR were both from $M D R-1$ and were derived from exon 2 (5' primer: residues $149-169)$ and exon 3 (3' primer: residues 253-228). For the lower PCR, the 5' primer was complimentary to the chromosome 4 sequences cloned and shown in Fig. 2 (5' primer: chromosome 4 residues 202-224), while the $3^{\prime}$ primer was the same as in the upper PCR. hybrids, to localize the novel gene (non-MDR- 1 sequences) to chromosome 4 (data not shown). This finding allowed chromosome preparations from bromodeoxyuridine-synchronized parental S48-3s cells and the drug resistant sublines to be analyzed by FISH using whole chromosome painting kits for chromosomes 4 (green) and 7 (orange). The results provided clear evidence of a translocation between chromosomes 4 and 7. Representative spreads are shown. The majority of parental cells contained two chromosomes 4 and three chromosomes 7; no cells showed rearrangements between 4 and 7 . In contrast, the majority of S48-3s/Adr 0.1 cells contained only one chromosome 4, two chromosomes 7, and two chromosomes showing a translocation between 4 and $7, t(4 q ; 7 q)$. Furthermore, the majority of S48-3s/Adr 10.0 cells also had one chromosome 4, two chromosomes 7 , and 1-2 chromosomes showing $\mathrm{t}(4 \mathrm{q} ; 7 \mathrm{q})$. In addition, in cells with two chromosomes showing $\mathrm{t}(4 \mathrm{q} ; 7 \mathrm{q})$, one chromosome demonstrated alternating portions of chromosomes 4 and 7 in tandem consistent with coamplification of sequences from chromosomes 4 and 7 . These results, together with the PCR analysis, are consistent with a translocation in the first step of the selection leading to activation of the MDR-1 gene and subsequent amplification of the hybrid gene.

Further confirmation of coexpression and coamplification of $M D R-1$ and the chromosome 4 sequences is shown in Fig. 5. Fig. $5 A$ shows expression of $M D R-1$ in parental cells at very low levels, with increases in the first step (S48-3s/Adr 0.1) coincident with the 4;7 translocation, and in subsequent steps (S483s/Adr1.0 and S48-3s/Adr10) as drug pressure was increased. In the latter two sublines, this increase accompanied amplification of $M D R-1$, as shown in the Southern analysis in Fig. 5 B, which used a cDNA fragment encoding residues 1306-2685 (coding sequence 1176-2555). Examination of Fig. $5 A$ also shows that the size of the hybrid $M D R-1$ transcript in the S48-3s Adr sublines is similar to that of native $M D R-1(\sim 4.5 \mathrm{~kb})$. This size was expected since the RNase protection experiment in Fig. 1 showed predominant (or exclusive) expression of the RNA lacking the 5' residues, and the cloning by RACE dem- onstrated that $250 \mathrm{bp}$ of chromosome 4 sequence had replaced the 204 missing MDR-1 bases (136 bases from 5' UTR and the first 68 bases of the coding sequence). Coexpression and coamplification of the chromosome 4 sequences are confirmed by the results in Fig. 5, $C$ and $D$. In Fig. $5 C$, a Northern analysis was performed using as a probe the $250 \mathrm{bp}$ cloned with the $5^{\prime}$ RACE methodology, which were shown to localize to chromosome 4. Expression of the chromosome 4 gene at very low levels is seen in parental S48-3s cells and in S48-3s/Adr 0.1 cells (probe size not ideal; better seen on longer exposures and in the RNase protection analysis shown in Fig. 5 E). Expression of the $250 \mathrm{bp}$ of sequence is increased in S48-3s/Adr1.0 and S48-3s/Adr10 cells, where high levels of expression were also detected with the $M D R-1$ probe. The increase in expression in S48-3s/Adr1.0 and S48-3s/Adr10 coincides with amplification of the chromosome 4 sequences, as shown in the Southern analysis in Fig. 5 D, which was hybridized with the same 250base pair probe. This amplification is coincident with the amplification observed in Fig. $5 B$ for $M D R-1$ and confirms the results in the FISH analysis. Finally, in Fig. $5 E$, an RNase protection analysis was performed using as a probe the fragment whose sequence is shown in Fig. $2 A$, and contains 95 base pairs from $M D R-1$ and 250 base pairs from chromosome 4 . RNA from parental S48-3s cells protects a fragment of $250 \mathrm{bp}$ in size corresponding to the chromosome 4 sequences contained in the probe. This result is consistent with the PCR analysis that demonstrated readily detectable expression of the chromosome 4 sequences in parental cells. In contrast, protection of the 95 base pairs of $M D R-1$ sequences contained within the probe were not observed (not shown in cropped figure), since $M D R-1$ expression in this cell line is very low; nor is protection of full length probe observed, since there is no expression of the hybrid RNA in parental cells. RNA from the resistant sublines protects full length probe representing the hybrid mRNA observed in the selected cell lines, and this increases with selection (as well as the 250 base pairs of chromosome 4 sequences that continue to be expressed from the nonrear- 


\section{S48-3s}

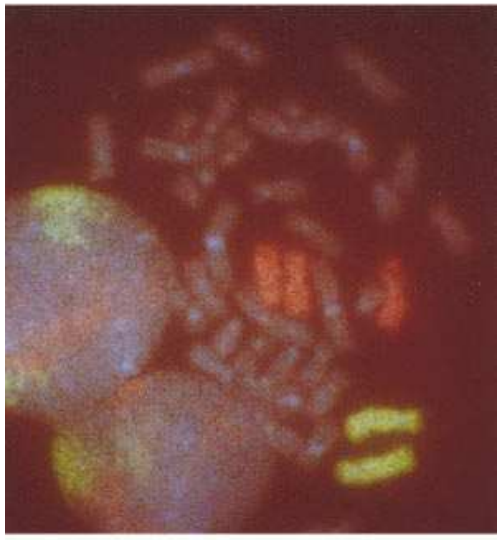

\section{S48-3s Adr 0.1}

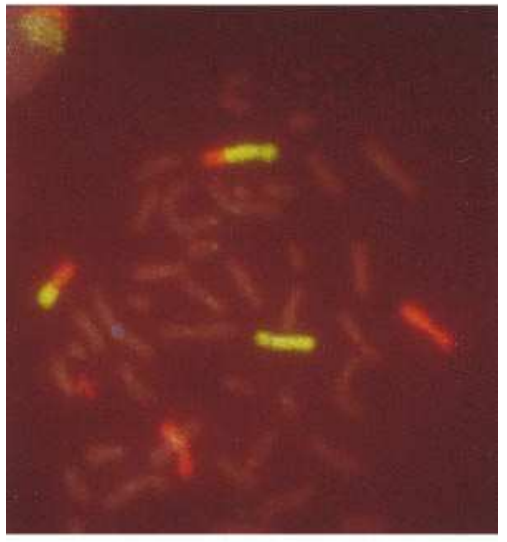

\section{S48-3s Adr 10}

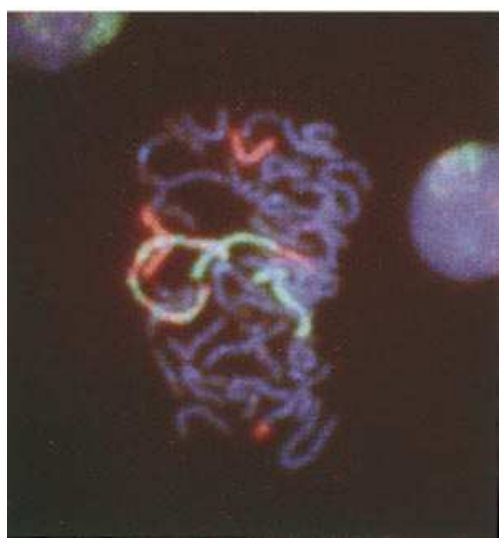

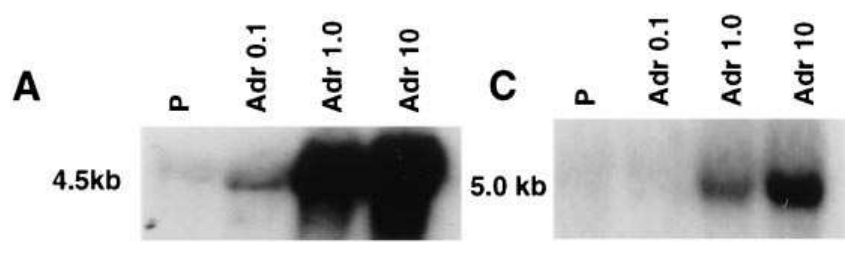

B

$16 \mathrm{~kb}$

$6.5 \mathrm{~kb}$

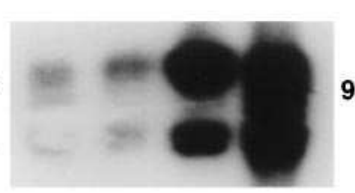

D

$9.3 \mathrm{~kb}$

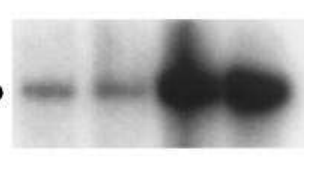

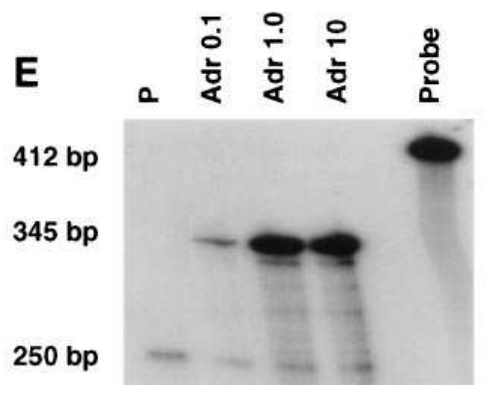

Figure 5. Northern and Southern blots and RNase protection analysis showing overexpression and amplification of $M D R-1$ and the sequences on chromosome 4 . $A$ and $B$ were probed with an $M D R-1$ probe containing residues 1306-2685 (coding sequence 1176-2555). $C$ and $D$ were probed with a 250-bp probe containing chromosome 4 sequences. $E$ is an RNase protection analysis in which the antisense probe was synthesized on a template containing 250 base pairs of chromosome 4 sequences in the $5^{\prime}$ end and 95 base pairs of MDR- 1 in the $3^{\prime}$ end. DNA was cut with HindIII. Coexpression and coamplification of $M D R-1$ and the sequences from chromosome 4 is shown. The RNase protection experiment shows that parental S48-3s cells protect only the 250 base pairs of chromosome 4 sequence, while the resistant cell lines protect the full length of the probe corresponding to chromosome 4 sequences fused to $M D R-1$.

Figure 4. FISH analysis using chromosomal painting kits for chromosomes 4 (green) and 7 (orange).

ranged chromosome 4 allele). These observations are further confirmed and extended in Tables I and II, which also contains additional data discussed below. The number of copies of the chromosome 4 sequence and the number of copies of $M D R-1$ in S48-3s Adr 10.0 cells relative to parental S48-3s cells was determined by quantitative PCR, using a methodology previously described and validated for $M D R-1 \mathrm{mRNA}$ expression (16). The sequences chosen were: (a) $M D R-1$ (coding): $M D R-1$

residues 546-831 and an intervening 574-bp intron (this sequence is $3^{\prime}$ to the site of translocation); (b) MDR-1 (promoter): residues -194 to -8 , which are located $5^{\prime}$ to the start of transcription and are $5^{\prime}$ to the site of translocation in the S48-3s Adr cells; $(c)$ chromosome 4 sequence: the novel sequence on chromosome 4; primers chosen generated a 119-bp fragment indicating no intron was present; and (d) $\mathrm{HO}-2$ : a sequence from the heme-oxygenase $2(\mathrm{HO}-2)$ gene was chosen as an internal control, because there was no reason to suspect a change in the copy number in this cell line, and because in an actinomycin-D-selected subline of S48-3s, a hybrid message composed of HO-2 and MDR-1 sequences had been observed as described below.

The results with S48-3s Adr 10 demonstrate that both the coding region of $M D R-1$ and the chromosome 4 gene have been amplified. Absence of amplification of residues -194 to -8 was expected since the site of translocation is $3^{\prime}$ to this region. This suggests $M D R-1$ expression is controlled by the chromosome 4 gene. Although all portions of an amplicon need not be amplified equally, the values of 6.9- and 9.2-fold for the MDR-1 (coding) and the chromosome 4 sequences, respectively, are consistent with comparable amplification. This is based on calculations that recognize that parental cells have 


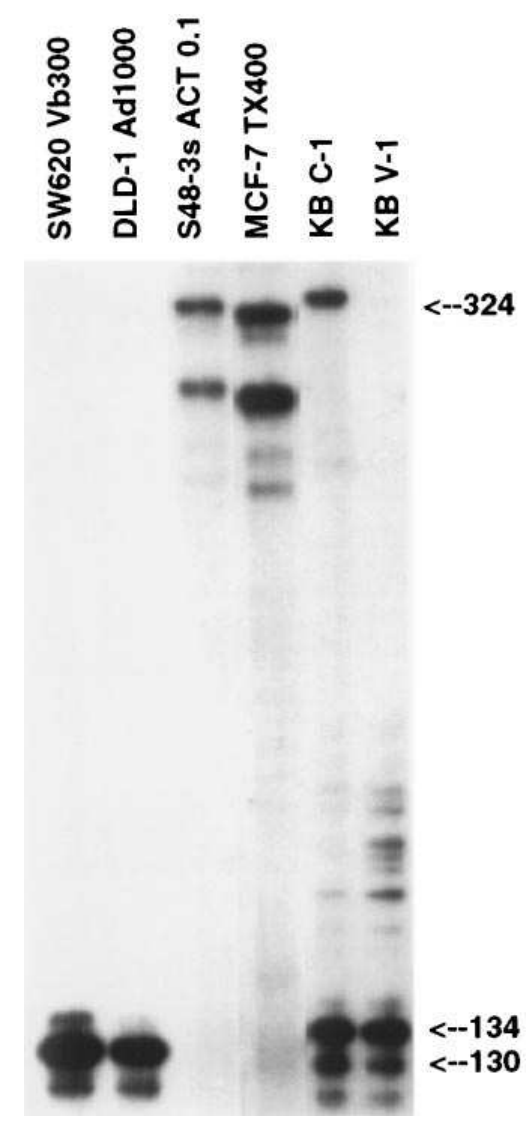

Figure 6. RNase protection using a 990-bp genomic probe containing residues -194 to +130 and 666 bp of intron sequences. Transcripts starting at native $M D R-1$ promoter protect 130- and 134-bp fragments. RNAs with start sites $5^{\prime}$ to this protect a 324-bp fragment. SW620 Vb300 and DLD-1 Ad1000 (colon cancer sublines) and KB C-1 and KB V-1 (HeLa sublines) are multidrug-resistant sublines.

three chromosomes 7 and two chromosomes 4 as shown by the FISH analysis above. $(M D R-1: 6.9 \times 3=20.7-2$ unaffected genes $=18.7$ amplified copies; chromosome 4 gene: $9.2 \times 2=$ $18.4-1$ unaffected gene $=17.4$ amplified copies.)

Random chromosomal rearrangements proximal to the start of transcription. Demonstration of a rearrangement in adriamycin-selected S48-3s cells provided a model for activation of MDR-1 that we explored in additional drug-selected cell lines. We recognized that such rearrangements would likely occur in the $5^{\prime}$ region of the gene (especially the 5' UTR), thus avoiding significant disruption of protein structure. We suspected that transcripts arising from an "upstream" promoter might be hybrid mRNAs of non-MDR-1 sequences fused to $M D R-1$ at residue -194 . To choose which RNAs to investigate, we relied on an RNase protection assay using as probe a 990-bp genomic fragment that contains residues -194 to +130 and promoter sequences surrounding +1 (6). This fragment has been used to discriminate transcripts from the putative "upstream" promoter from those of the "downstream" (or $M D R-1)$ promoter. Transcripts arising at the $M D R-1$ promoter protect 130 and 134 bp (start sites +1 and -4 ) as shown in Fig. 6 for multidrug resistant SW 620 Vb300, DLD-1 Ad1000, and KB V-1. In contrast, transcripts arising upstream protect $324 \mathrm{bp} \mathrm{(-194} \mathrm{to}$ +130 ) after splicing at -194 . We identified among drugselected sublines a subset with "upstream" start sites as shown in Fig. 6: S48-3s/ACT 0.1 (actinomycin-D-selected S48-3s), MCF TX400 (paclitaxel-resistant MCF-7), and KB C-1. 5' extension analysis using RNA from these cell lines gave different length products, suggesting different start sites (not shown). Using the 5' RACE system and primers GSP1 and GSP2 to clone the $5^{\prime}$ regions of these transcripts, different size products were also obtained. Fig. 7 shows the results obtained from two 5' RACE products. The source of the RNAs were MCF TX400 and S48-3s ACT 0.1. The sequences 5' to -194 (Fig. 7, $A$ and $B$ ) differed from each other and from that for KB C-1. Searching Genbank/EMBL/DDBJ, homology to two different genes was found. Sequences $5^{\prime}$ to -194 in MCF TX400 matched the 5' UTR of CDP alternately spliced product $(C A S P)$, an alternately spliced variant of CCAAT displacement protein $(C D P)$, a gene previously localized to $7 \mathrm{q} 22$ (17, 18). Sequences 5' of -194 in S48-3s ACT 0.1 cells were homologous to the 5' UTR of heme-oxygenase 2 (HO-2), which is on chromosome 16 (19). As shown in Fig. $7 \mathrm{C}, \mathrm{CASP}$ and $\mathrm{HO}-2$ are expressed in parental cells at higher levels than $M D R-1$ (which is not detectable in MCF-7 parental cells after 50 cycles of amplification). Expression of the hybrid message composed of $C A S P$ or $H O-2$ fused to -194 of $M D R-1$ is shown in Fig. 7, $D$ and $E$. Hybrid messages were detected only in the resistant cells (after 20 cycles of amplification), and not in parental cells (even after 50 cycles). Thus, expression of hybrid messages is significantly greater in the resistant cells. These results are similar to those observed in the $\mathrm{S} 48-3 \mathrm{~s}$ adriamycin selection.

These results were confirmed in several ways. In MCF-7 TX400 cells, a hybrid PCR product was obtained using CASP sequences $(-15$ to +3$)$ as a $5^{\prime}$ primer, and an oligomer corresponding to $M D R-1$ residues -127 to -145 as a $3^{\prime}$ primer. This hybrid product was found only in MCF TX400, and not in 13 other multidrug-resistant sublines (not shown). In addition, sequence of the hybrid product showed $C A S P$ sequences fused to $M D R-1$ at -194 . Furthermore, coamplification of $C A S P$ and $M D R-1$ could be demonstrated. As summarized in Tables I and II, a high relative copy number of both $M D R-1$ and $C A S P$ sequences are found in MCF TX400 compared with parental MCF-7 cells. Differences between MDR-1 and CASP may be explained by differential amplification of different regions of an amplicon.

Likewise, in S48-3s ACT 0.1 cells, a hybrid PCR product was obtained using $\mathrm{HO}-2$ sequences $(-22$ to -5$)$ as a $5^{\prime}$ primer and $M D R-1(-127$ to -145$)$ as a $3^{\prime}$ primer. The hybrid product was found only in S48-3s ACT 0.1 and not in 13 other multidrug-resistant sublines (not shown). And sequence confirmed that $H O-2$ was fused to $M D R-1$ at -194 . However, in S48-3s ACT 0.1, coamplification was not demonstrated since neither $M D R-1$ nor $H O-2$ is amplified (lack of $M D R-1$ amplification consistent with Southern blotting, not shown).

Thus, in these three cell lines, hybrid messages composed of non-MDR- 1 sequences and $M D R-1$ were detected. In S48$3 \mathrm{~s} / \mathrm{Adr}$ cells, a rearrangement in intron 2 was demonstrated, while in MCF TX400 and S48-3s ACT 0.1 cells, the non-MDR-1 sequences were fused to $M D R-1$ at residues -194 in the $5^{\prime}$ UTR, predicting that an intact protein should be synthesized. All three cell lines displayed a multidrug-resistant phenotype with cross-resistance to several drugs, and by FACS ${ }^{\circledR}$ analysis were shown to have high levels of P-glycoprotein. These results are shown in Fig. 8, which shows the results of surface staining with the monoclonal antibody, MRK-16. As can be seen, all three cell lines, including S48-3s/Adr 10, whose P-glycoprotein lacks the $\mathrm{NH}_{2}$-terminal 68 residues, have high levels of surface staining for P-glycoprotein, confirming that high levels of protein are present and properly localized. It should be noted that just as in the S48-3s/Adr sublines where the $M D R-1$ message that was expressed was predominantly (or exclusively) the hybrid message, so too in MCF TX400 and S48-3s 
A.

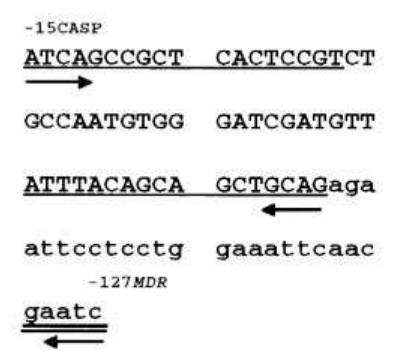

B.

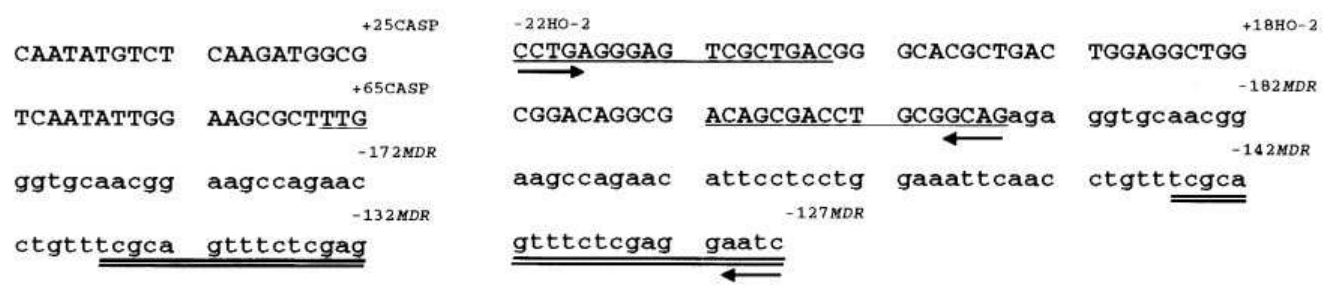

S48-3s ACT 0.1

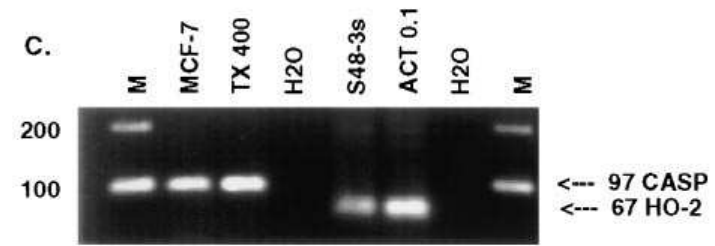

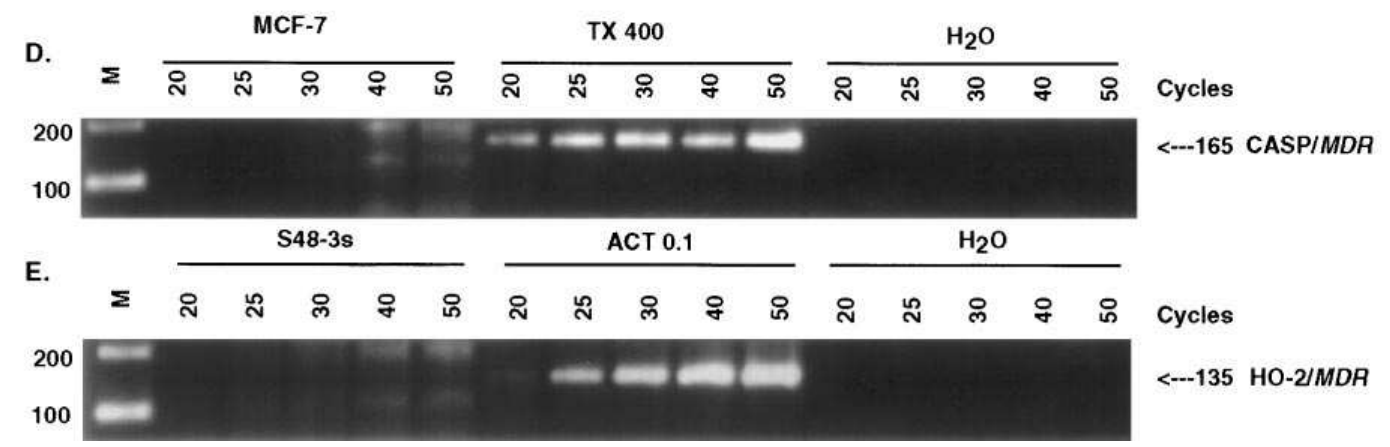

Figure 7. ( $A$ and $B)$ Nucleotide sequences of residues (upper case) $5^{\prime}$ to $M D R-1$ residue -194 (MDR-1, lower case) in MCF TX400 and S48-3s/ ACT 0.1. Underlined sequences identify primers used in the PCR shown in $C-E$. $(C)$ Expression of 97-bp CASP fragment in MCF-7 and MCF TX400 using CASP primers underlined in $A$, and expression of 67-bp HO-2 fragment in S48-3s and S48-3s/ACT 0.1 using HO-2 primers underlined in B. (D) Expression of 165-bp CASP/MDR-1 hybrid by PCR in MCF TX400 using a 5' CASP primer (underlined) and a 3' MDR-1 primer (double underlined) in $A$. No hybrid fragment detected in parental MCF-7 cells. (E) Expression of 135-bp HO-2/MDR-1 hybrid by PCR in S48-3s ACT 0.1 using a 5' HO-2-specific primer (underlined) and 3' MDR-1 primer (double underlined) in B. No hybrid fragment detected in S48-3s parental cells.

ACT 0.1 cells is there predominant (or exclusive) expression of hybrid message. The evidence for this is seen in Fig. 6, which shows no protection of fragments of 130 and 134 base pairs, as are observed when transcription starts at the normal start site for $M D R-1$. Thus, in all the cell lines, these hybrid messages are translated into surface P-glycoproteins that confer resistance.

Encouraged by these results and similar observations in three other drug-selected sublines (not shown), we began to examine clinical samples to determine if similar rearrangements occur in resistant tumors. Two lymphoblastic leukemia samples from patients with disease that was proven to be refractory to daunomycin and vincristine were studied. These samples had been previously shown to have "upstream" start sites, and to express P-glycoprotein on their surface (20) and, when analyzed, were found to have hybrid messages isolated with the 5' RACE system and primers GSP1 and GSP2. Fig. 9 shows the sequences fused to residue -194 of $M D R-1$ in leukemia samples ALL 1 and ALL 2. When Genbank/EMBL/ DDBJ was searched, homology to the 5' UTR-1 sequence of Nuclear respiratory factor-1 (NRF-1) was found for ALL 1. No homology was found for ALL 2. However, somatic cell hybrid analysis mapped the novel sequence in ALL 2 to chromosome 1. Using primers corresponding to NRF-1 and the chromo- some 1 sequences, expression of NRF-1 (ALL 1) and chromosome 1 sequences (ALL 2) were readily detectable (Fig. 9 B) by PCR in all RNA samples examined (70-bp fragment for $N R F-1$; 177-bp fragment for chromosome 1 sequence). Thus, as in the drug-resistant cell lines, the sequences $5^{\prime}$ of $M D R-1$ are expressed endogenously in numerous RNAs. Furthermore, PCR analysis shows expression of the unique hybrid sequences in RNA from each acute leukemia sample and not in other RNA samples (137-bp hybrid message for ALL 1, and 244-bp hybrid message for ALL 2). Neither of these specific hybrids was detected by PCR in 13 multidrug-resistant cell lines with high levels of MDR-1 ( 3 shown), nor in the other leukemia. Unfortunately a sample before treatment was not available.

\section{Discussion}

The problem of clinical drug resistance has stimulated interest in the mechanisms of chemotherapeutic tolerance. In the present study, activation of $M D R-1$ in adriamycin-selected S48-3s cells occurred after a 4;7 translocation that resulted in a juxtaposition of the $M D R-1$ gene $3^{\prime}$ to a transcriptionally active chromosome 4 gene. This finding prompted additional studies to determine if gene rearrangements had occurred in 

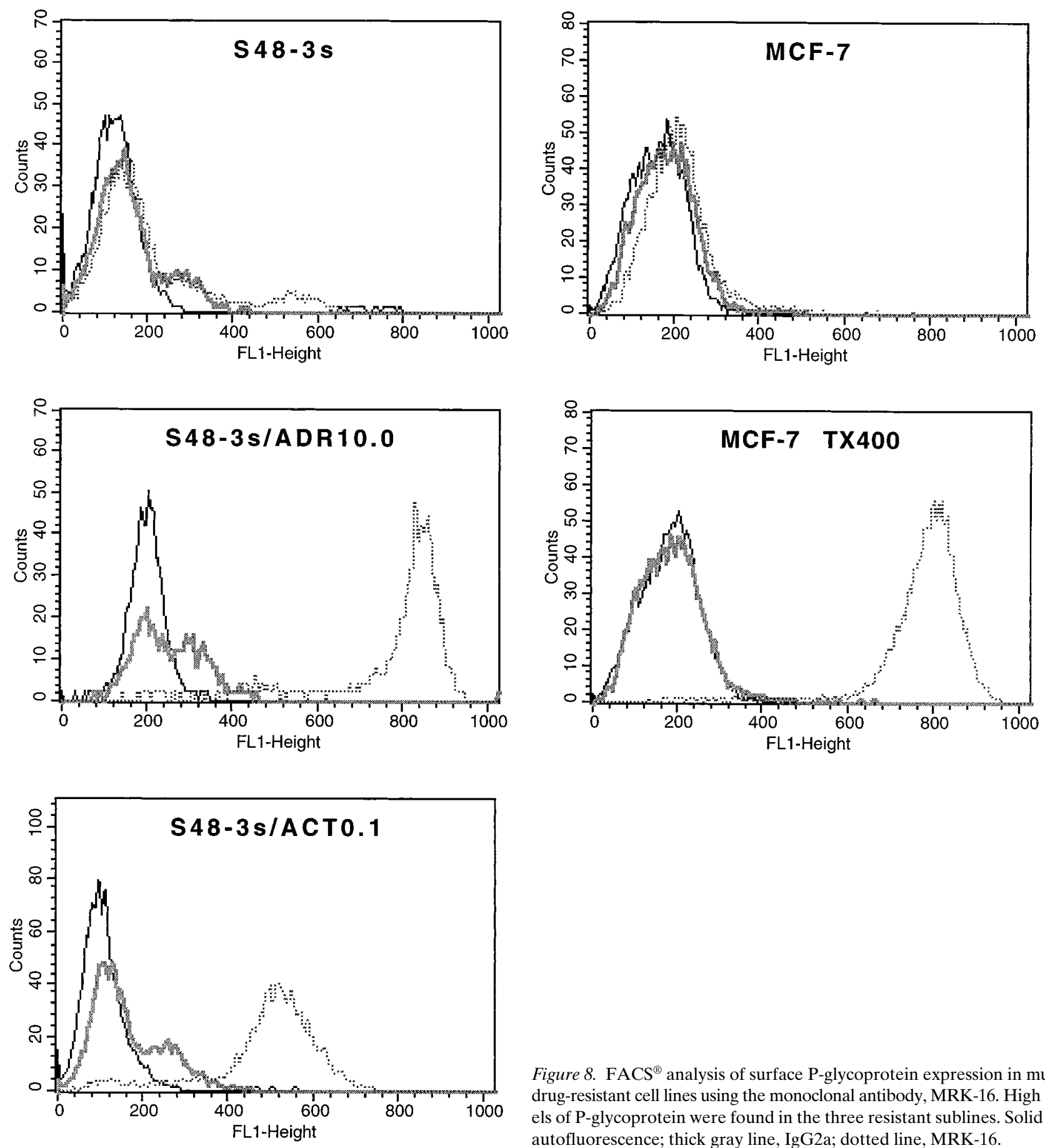

Figure 8. FACS ${ }^{\circledR}$ analysis of surface P-glycoprotein expression in multidrug-resistant cell lines using the monoclonal antibody, MRK-16. High levels of P-glycoprotein were found in the three resistant sublines. Solid line, autofluorescence; thick gray line, IgG2a; dotted line, MRK-16.

any other cell line. Similar observations in other drug-resistant cell lines and two patient samples provide a mechanism for overexpression of $M D R-1$ during drug selection: gene rearrangement leading to activation of $M D R-1$.

Evidence that acquired mutations usually confer small advantages (21-23) suggests that increased expression is more important than acquired mutations. An explanation for how increased expression can occur in parental cells with low or undetectable levels of $M D R-1$ expression is provided in the present study. The initial observations were made in the adriamycin-selected S48-3s cell line. In this selection, deletion of the

$68 \mathrm{NH}_{2}$-terminal residues of the coding sequence as a result of a 4;7 translocation increased expression and was advantageous. After the translocation, expression of $M D R-1$ was controlled by the chromosome 4 gene, which has a higher endogenous expression. That this was not an isolated finding was documented when additional cell lines were examined. In MCF TX400 cells, a hybrid message composed of sequences from the 5' UTR of CASP fused to MDR-1 -194 was identified, and in S48-3s ACT 0.1 cells, the hybrid message contained sequences from the $5^{\prime}$ UTR of the heme-oxygenase 2 gene fused to $M D R-1-194$. Thus, gene rearrangements oc- 


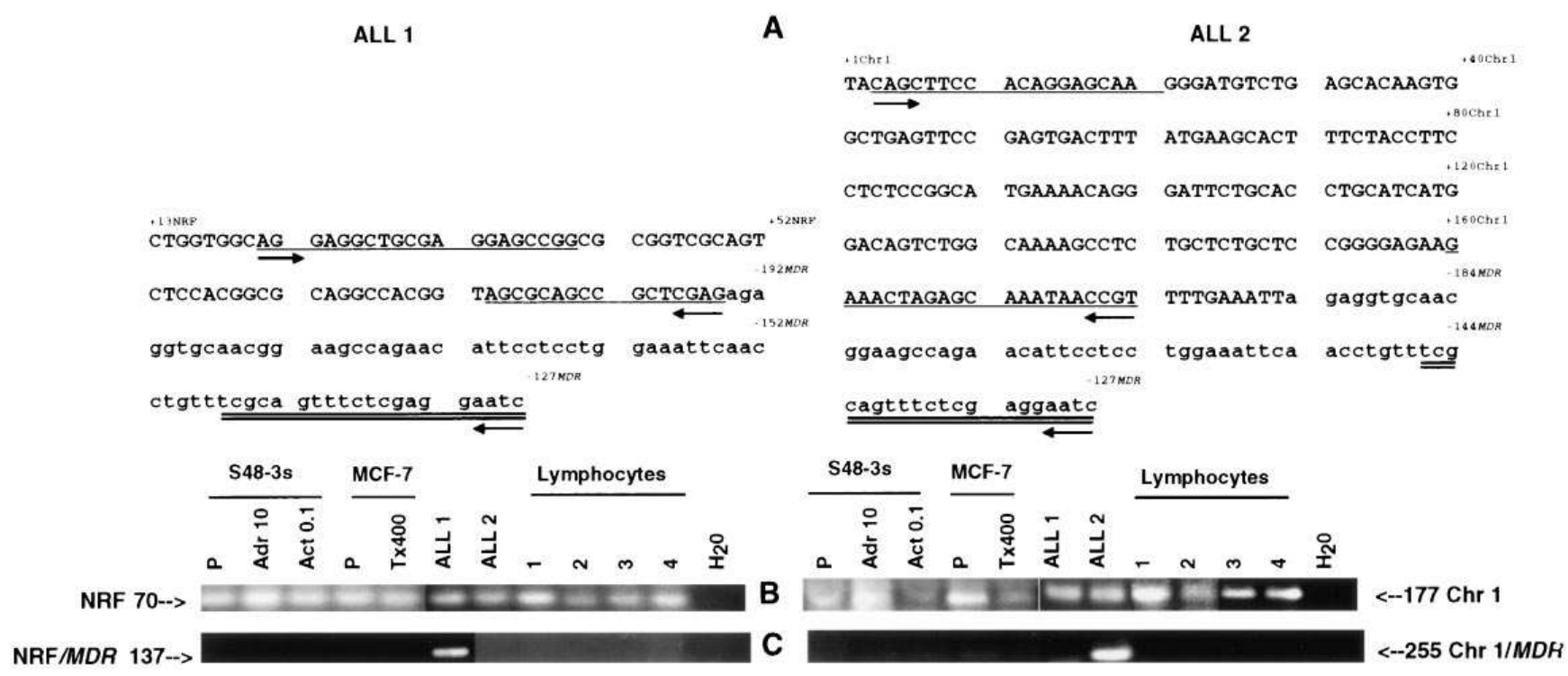

Figure 9. (A) Nucleotide sequence of residues (upper case) 5' to MDR-1 residue -194 (MDR-1, lower case) in two acute lymphocytic leukemia patients (ALL 1 and ALL 2). Underlined sequences identify primers used in PCR. (B) Expression of 70-bp NRF-1 and 177-bp Chr1 (chromosome 1) sequences in cell lines, normal lymphocytes, and acute leukemia patients using primers corresponding to NRF-1 sequences in ALL 1 and chromosome 1 sequences in ALL 2. (C) Expression of $N R F / M D R$ and Chr1/MDR hybrids detected only in the respective acute leukemia patients. The 5' primers used are from NRF-1 sequences and chromosome 1 sequences (underlined). The $3^{\prime}$ primer is from MDR-1 (double underline).

curred during drug selection resulting in hybrid genes and increased expression, or in the case of MCF TX400 cells, initial activation of $M D R-1$. The PCR evidence indicates these rearrangements were unlikely to be present in any parental cell. Thus, these events represent examples of acquired resistance. A previous report describing an unusual DNA rearrangement in murine multidrug-resistant $\mathbf{J} 774.2$ cells may have played a role in $M D R-1$ activation in that model (24). Other reports of DNA rearrangements in the $M D R-1$ gene have also been described (25-27). Finally, in multidrug-resistant P-388 cells, "IAP integration leading to $M D R-3$ transcriptional activation was the initial mutagenic event during drug selection" (28).

Further studies will be required to better understand the role of hybrid $M D R-1$ messages in transcriptional activation. While this has not been previously recognized as a mechanism of $M D R-1$ activation, similar events have been described in other settings $(29,30)$. In the case of $M D R-1$, it provides a means of increasing $M D R-1$ expression in cells with low levels of expression, or of activating a silent $M D R-1$ gene such as is found in MCF-7 cells and lymphoblasts. In this regard, it should be noted that, to date, transcriptional start sites upstream of the native $M D R-1$ promoter, such as are observed in the cells with hybrid messages, have not been identified in sublines isolated from DLD-1, SW620, and LS180 human colon carcinoma cells, which have higher levels of endogenous $M D R-1$; nor have they been found in samples from renal or adrenocortical cancers that express high levels of $M D R-1$ de novo (Fig. 6, reference 31, and not shown).

Preliminary studies indicate the site of rearrangement is not the same in the various cell lines. In S48-3s Adr cells, the site was intron 2. In the MCF-7 TX400 cells, the evidence suggests that the rearrangement occurred $5^{\prime}$ to an EcoRI site $8 \mathrm{~kb}$ $5^{\prime}$ of the start of transcription $(+1)$ (not shown). More distant rearrangements may also occur since the upstream promoter where upstream transcription starts in $\mathrm{KB} \mathrm{C}-1$ has been reported to be a minimum of $18 \mathrm{~kb}$ from +1 (32). Future studies will identify the diverse sites of rearrangements that result in activation of $M D R-1$.

Although more extensive screening will be necessary to establish the frequency of this phenomenon clinically, the results in two patients support further investigations. The evidence suggests these hybrid messages are unique to these leukemia samples. In the case of ALL 1 , the non-MDR-1 sequences are from the 5' UTR-1 of NRF-1. This is similar to the results observed with $C A S P$ and $H O-2$ and consistent with control of $M D R-1$ expression by the non-MDR-1 promoter.

In summary, the work described herein demonstrates random chromosomal rearrangements with generation of hybrid $M D R-1$ messages as a mechanism for activation of $M D R-1$ expression. It is hoped these characterizations will help to further our understanding of drug resistance.

\section{Acknowledgments}

The authors thank Rosarelis Torres and Dr. Michael Polymeropoulos for chromosomal mapping, Dr. Zhirong Zhan for PCR quantitation, Dr. David Poplack and Diane Cole for the ALL samples, and Rob Robey for the FACS ${ }^{\circledR}$ analysis.

\section{References}

1. Juliano, R.L., and V. Ling. 1976. A surface glycoprotein modulating drug permeability in Chinese hamster ovary cell mutants. Biochim. Biophys. Acta. 455:152-162.

2. Beck, W.T., T.J. Mueller, and L.R. Tanzer. 1979. Altered surface membrane glycoproteins in vinca alkaloid-resistant human leukemic lymphoblasts. Cancer Res. 39:2070-2076.

3. Ling, V., and L.H. Thompson. 1974. Reduced permeability in CHO cells 
as a mechanism of resistance to colchicine. J. Cell Physiol. 83:103-116.

4. Shen, D.W., A. Fojo, J.E. Chin, I.B. Roninson, N. Richert, I. Pastan, and M.M. Gottesman. 1986. Human multidrug-resistant cell lines: increased mdr-1 expression can precede gene amplification. Science (Wash. DC). 232:643-645.

5. Lai, G.-M., Y.-N. Chen, L.A. Mickley, A.T. Fojo, and S.E. Bates. 1991. P-glycoprotein expression and schedule dependence of adriamycin cytotoxicity in human colon carcinoma cell lines. Int. J. Cancer. 49:696-703.

6. Ueda, K., I. Pastan, and M.M. Gottesman. 1987. Isolation and sequence of the promoter region of the human multidrug-resistance (P-glycoprotein) gene. J. Biol. Chem. 262:17432-17436.

7. Winter, E., C. Yamamoto, M. Almoguera, and T. Perucho. 1985. A method to detect and characterize point mutations in transcribed genes: amplification and overexpression of the mutant c-Ki-ras allele in human tumor cells. Proc. Natl. Acad. Sci. USA. 82:7575-7579.

8. Ohara, O., R.L. Dorit, and W. Gilbert. 1989. One sided polymerase chain reaction: the amplification of cDNA. Proc. Natl. Acad. Sci. USA. 85:8998-9002.

9. Murphy, L.D., C.E. Herzog, J.B. Rudick, A.J. Fojo, and S.E. Bates. 1990. Use of the polymerase chain reaction in the quantitation of mdr-1 gene expression. Biochemistry. 29:10351-10356.

10. Polymeropoulos, M.H., H. Xiao, J.M. Sikela, M. Adams, J.C. Venter, and C.R. Merril. 1993. Chromosomal distribution of 320 genes from a brain cDNA library. Nat. Genet. 4:2-7.

11. Modi, W.S., W.G. Nash, A.C. Ferrari, and S.J. O'Brien. 1987. Cytogenetic methodologies for gene mapping and comparative analyses in mammalian cell culture systems. Gene Anal. Tech. 4:75-85.

12. Fuscoe, J.C., J.S. McNinch, C.C. Collins, and M.A. VanDilla. 1989. Human chromosome-specific DNA libraries: construction and pursuit analysis. Cytogenet. Cell Genet. 50:211-215.

13. Mickley, L.A., S.E. Bates, N.D. Richert, S. Currier, S. Tanaka, F. Foss, N. Rosen, and A.T. Fojo. 1989. Modulation of the expression of a multidrug resistance gene (mdr-1/P-glycoprotein) by differentiating agents. J. Biol. Chem. 264:18031-18040.

14. Herzog, C.E., J.B. Trepel, L.A. Mickley, S.E. Bates, and A.T. Fojo. 1992. Various methods of analysis of mdr-1/P-glycoprotein in human colon cancer cell lines. J. Natl. Cancer Inst. 84:711-716.

15. Chen, C., D. Clark, K. Ueda, I. Pastan, M.M. Gottesman, and I.B. Roninson. 1990. Genomic organization of the multidrug resistance (MDR1) gene and origin of P-glycoprotein. J. Biol. Chem. 265:506-514.

16. Alvarez, M., K. Paull, A. Monks, C. Hose, J.S. Lee, J. Weinstein, M. Grever, S. Bates, and T. Fojo. 1995. Generation of a drug resistance profile by quantitation of mdr-1/P-glycoprotein in the cell lines of the National Cancer Institute Anticancer Drug Screen. J. Clin. Invest. 95:2205-2214.

17. Skalnik, D.G., E.C. Strauss, and S.H. Orkin. 1991. CCAAT displacement protein as a repressor of the myeolomonocytic-specific gp91-phox gene promoter. J. Biol. Chem. 266:16736-16744.

18. Scherer, S.W., E.J. Neufeld, M.-J. Lievens, S.H. Orkin, J. Kim, and L.-C. Tsui. 1993. Regional localization of the CCAAT displacement protein gene (CUTL1) to 7q22 by analysis of somatic cell hybrids. Genomics. 15:695-696.

19. Kutty, R.K., G. Kutty, I.R. Rodriguez, G.J. Chader, and B. Wiggert. 1994 Chromosomal localization of human heme oxygenase genes: heme oxygenase-1 (HMOX1) maps to chromosome 22q12 and heme oxygenase-2 (HMOX2) maps to chromosome 16p13.3. Genomics. 20:513-516.

20. Rothenberg, M.L., L.A. Mickley, D.E. Cole, F.M. Balis, T. Tsuruo, D.G. Poplack, and A.T. Fojo. 1989. Expression of the mdr-1/P-170 gene in patients with acute lymphoblastic leukemia. Blood. 74:1388-1395.

21. Choi, K., C.J. Chen, M. Kriegler, and I.B. Roninson. 1988. An altered pattern of cross-resistance in multidrug resistant human cells results from spontaneous mutations in the mdr-1 (P-glycoprotein) gene. Cell. 53:519-529.

22. Devine, S.E., V. Ling, and P.W. Melera. 1992. Amino acid substitutions in the sixth transmembrane domain of P-glycoprotein alter multidrug resistance. Proc. Natl. Acad. Sci. USA. 89:4564-4568.

23. Gros, P., R. Dhir, J. Croop, and F. Talbot. 1991. A single amino acid substitution strongly modulates the activity and substrate specificity of the mouse mdr1 and mdr3 drug efflux pumps. Proc. Natl. Acad. Sci. USA. 88:72897293.

24. Cohen, D., S.M. Higman, S.I.-H. Hsu, and S.B. Horwitz. 1992. The involvement of a LINE-1 element in a DNA rearrangement upstream of the $m d r 1$ a gene in a Taxol multidrug-resistant murine cell line. J. Biol. Chem. 267: 20248-20254.

25. Roninson, I.B., J.E. Chin, K. Choi, P. Gros, D.E. Housman, A. Fojo, D.-W. Shen, M.M. Gottesman, and I. Pastan. 1986. Isolation of human mdr DNA sequences amplified in multidrug-resistant KB carcinoma cells. Proc. Natl. Acad. Sci. USA. 83:4538-4542.

26. Ruiz, J.C., K. Choi, D.D. Von Hoff, I.B. Roninson, and G.M. Wahl 1989. Autonomously replicating episomes contain mdr1 genes in a multidrugresistant human cell line. Mol. Cell. Biol. 9:109-115.

27. Schoenlein, P.V., D.W. Shen, J.T. Barrett, I. Pastan, and M.M. Gottesman. 1992. Double minute chromosomes carrying the human multidrug resistance 1 and 2 genes are generated from the dimerization of submicroscopic circular DNAs in colchicine-selected KB carcinoma cells. Mol. Biol. Cell. 3: 507-520.

28. Lepage, P., A. Devault, and P. Gros. 1993. Activation of the mouse mdr3 gene by insertion of retroviruses in multidrug-resistant p388 tumor cells. Mol. Cell. Biol. 13:7380-7392.

29. Poirel, H., K. Rack, E. Delabesse, I. Radford-Weiss, X. Troussard, C. Debert, D. Leboeuf, C. Bastard, F. Picard, A. Veil-Buzyn, G. Flandrin, O. Bernard, and E. Macintyre. 1996. Incidence and characterization of MLL gene (11q23) rearrangements in acute myeloid leukemia M1 and M5. Blood. 87: 2496-2505.

30. Chang, K.-S., J. M. Trujillo, T. Ogura, C.M. Castiglione, K.K. Kidd, S Zhao, E.J. Freireich, and S.A. Stass. 1991. Rearrangement of the retinoic acid receptor gene in acute promyelocytic leukemia. Leukemia (Basingstoke). 5: 200-205.

31. Bates, S.E., C.Y. Shieh, L.A. Mickley, H.L. Dichek, A. Gazdar, D.L. Loriaux, and A.T. Fojo. 1991. Mitotane enhances cytotoxicity of chemotherapy in cell lines expressing a multidrug resistance gene (mdr-1/P-glycoprotein) which is also expressed by adrenocortical carcinomas. J. Clin. Endocrinol. Metab. 73:18-29.

32. Chin, J.E., R. Soffir, K.E. Noonan, K. Choi, and I.B. Roninson. 1989 Structure and expression of the human MDR (P-glycoprotein) gene family. Mol. Cell. Biol. 9:3808-3820. 